\title{
Duration-dependent effects of high dose of phthalate exposure on semen quality in adult male rats
}

\author{
Victor Emojevwe ${ }^{1,2}$, Alexander O Naiho ${ }^{1}$, Eze $\mathrm{K}$ Nwangwa ${ }^{1}$, Mega O Oyovwi ${ }^{1,3}$, Kenneth $\mathrm{K}$ Anachuna ${ }^{1}$, Ejime \\ Agbanifo-Chijiokwu ${ }^{1}$, Terela M E Daubry ${ }^{1}$ \\ ${ }^{1}$ Delta State University, Abraka, Delta State, Nigeria \\ 'University of Medical Sciences, Ondo City, Ondo State, Nigeria \\ ${ }^{3}$ Achievers University, Owo, Ondo State, Nigeria
}

\begin{abstract}
Objective: To determine the length of exposure to high doses of phthalate that might affect sperm quality in adult male Wistar rats.

Methods: Forty-two (42) adult male Wistar rats (weighing 150-200 g) were randomly assigned into six groups $(n=7)$ : Group A received $0.5 \mathrm{~mL}$ of distilled water - placebo - and served as controls; groups B, C, D, E and $F$ received Phthalate $(750 \mathrm{mg} / \mathrm{kgbw})$ for $1,3,5,7$ and 9 weeks, respectively. The data obtained from the study was expressed as Mean \pm SEM with a $p$-value $<0.05$ considered significant. The data was analyzed with one-way analysis of variance (ANOVA) followed by Tukey's post-hoc test using GraphPad Prism, version 8.

Results: The results showed a statistically significant $(p<0.05)$ decrease in testicular weight in the rats exposed to $750 \mathrm{mg} / \mathrm{kg}$ of phthalate for 3, 5, 7 and 9 weeks when compared with the controls. Sperm count, motility and viability were also significantly $(p<0.05)$ reduced, while sperm cells with abnormal morphology had increased counts in the groups exposed for 3, 5, 7 and 9 weeks when compared with controls. Serum zinc and magnesium were also significantly reduced $(p<0.05)$ in the subjects treated for $1,3,5,7$ and 9 weeks when compared with controls.

Conclusions: The dosage of phthalate adopted in this study was deleterious to testicular function when rats were exposed to it for as short a period as three weeks.
\end{abstract}

Keywords: phthalate, testicular toxicity, sperm count, sperm viability, motility, morphology

\section{INTRODUCTION}

Endocrine disrupting chemicals (EDCs) have been attributed with potential deleterious effects on reproduction by interfering with the biosynthesis, activities or elimination of the reproductive and other natural hormones in the body (Nassouri et al., 2012). The effects from EDCs are common because of the high level of these substances in the environment (Silins \& Högberg, 2011), and as such humans are exposed to them from conception to old age. A common example of such substances is di(2-ethylhexyl) phthalate, a compound commonly used as a plasticizer in polyvinylchloride (PVC) plastics found in personal care products and medical devices. It accounts for a significant percentage of the total phthalates used worldwide (Kamrin, 2009).

These chemicals have been identified to cause multi-organ damage in humans and animals through a number of mechanisms. One such mechanism manifests through increased rates of genes expression in Peroxisome Proliferator-Activated Receptors, which in turn leads to abnormal cell growth and carcinogenesis (Yavaşoğlu et al., 2014). Another path occurs through oxidative stress in the mitochondria by way of generation of Reactive Oxygen Species (ROS). The ensuing DNA damage may disrupt cellular proteins and increase the rate of lipid peroxidation (Erkekoglu et al., 2014).

Epidemiological (Benjamin et al., 2017) and animal (Yavaşoğlu et al., 2014; Esteves, 2014; Lee et al., 2007) studies have associated phthalates with infertility, where they are said to interfere with normal functioning of the gonads. Such effect in human males is normally diagnosed by semen analysis that provides information on the functional status of the testes, epididymis, seminiferous tubules and accessory sex glands (Zhang et al., 2018). In previous studies, different dosages of various phthalates have also been found to induce reproductive toxicity (Chang et al., 2015; Wu et al., 2018; Lee et al., 2007), although none of the previous studies was able to establish the exact length of exposure that might be deleterious to testicular function or the mechanism of action of phthalates. It is therefore pertinent for this study to evaluate the possible mechanisms and lengths of exposure that might affect semen quality in male Wistar rats.

\section{MATERIALS AND METHODS}

\section{Animals}

This study included 42 adult Male Wistar rats weighing 150-250 g (aged 5.5 \pm 0.5 months) procured and maintained in the Animal House of the University of Medical Sciences, Ondo. The rats were allowed to acclimatize for two weeks before the commencement of administration. The animals were housed in standard laboratory cages and allowed free access to standard commercial rat pellets with standard composition purchased from Top Feed iwu, Edo State and water ad libitum. They were maintained on a 12:12 hour light and dark cycle at $5^{\circ} \mathrm{C} \pm 2^{\circ} \mathrm{C}$.

\section{Experimental Design}

The 42 male Wistar rats were randomly assigned into six groups $(n=7)$. Group A (untreated) served as control and received $0.5 \mathrm{~mL}$ of distilled water placebo, while group $B$ received Phthalate $(750 \mathrm{mg} / \mathrm{kgbw})$ for 1 week, group C received Phthalate $(750 \mathrm{mg} / \mathrm{kgbw})$ for 3 weeks, group D received phthalate $(750 \mathrm{mg} / \mathrm{kgbw})$ for 5 weeks, group $\mathrm{E}$ received phthalate $(750 \mathrm{mg} / \mathrm{kgbw})$ for 7 weeks, and group $\mathrm{F}$ received phthalate $(750 \mathrm{mg} / \mathrm{kgbw})$ for 9 weeks.

\section{Administration of phthalate}

The phthalate used in this study was di-(2-ethylhexyl) phthalate purchased from Sigma Aldrich, USA (catalog number D201154-2L). The chemical is a viscous liquid, and was administered to the animals with the aid of an orogastric cannula at a dosage of $750 \mathrm{mg} / \mathrm{kg}$ body weight per day, following the method described in a preliminary study performed to determine the L.D 50 of Phthalate and the modifications of the established dose proposed by Lee 
et al. (2007). Using the computer software Omni dosage calculator (https://www.omnicalculator.com/health/dosage), the daily dosage of the chemical was estimated from the weight of the animals. Treatment of the animals was done between $7 \mathrm{am}$ to 11 am daily.

\section{Sample Collection}

At the end of $1,3,5,7$ or 9 weeks, the animals were fasted and euthanized. The testes and epididymis were carefully dissected and weighed on an electronic weighing scale, while the epididymis was used in semen analysis.

\section{Semen analysis}

For sperm count the caudal epididymis was homogenized in formalin saline and the sperm count was carried out using the improved Neubauer counting chamber (LABART, Germany). Sperm was examined under a light microscope at 40x magnification; the different fields were evaluated and sperm count was calculated based on the formula described by Omirinde et al. (2019):

Sperm count $=\frac{(\text { No of sperm counted } \times \text { Diluation })}{\text { Volume of squares } \times 5}$ in million $/ \mu \mathrm{L}$ or million $/ \mathrm{mlm}^{3}$

Sperm motility was determined by the conventional method described by Khatun et al. (2018). After the sperm was squeezed on the pre-warmed slide, two drops of warm $2.9 \%$ sodium citrate were added to it. The slide was then covered with a cover slip and examined under the microscope using 4x0 objective lens with reduced light (Khatun et al., 2018). Sperm Viability (Live/Death Raito) was assessed by observing the percentage of spermatozoa in a unidirectional progressive movement over a field on a slide under the light microscope fitted with a camera using the Eosin/Nigrosin stain (Omirinde et al., 2019). Sperm morphology was analyzed by collecting a thin smear of the sperm sample on a clean slide fixed with $95 \%$ ethanol allowed to air dry. The fixed slide was then sequentially immersed into different concentrations of ethanol and stained with Harris hematoxylin, G-6 orange stain and EA50 green stain for one minute. The slide was then examined under a microscope at 40x magnification; 200 sperm were assessed and sperm abnormalities were expressed in percentages (Omirinde et al., 2019; Yu et al., 2018).

\section{Electrolyte level determination}

$\mathrm{Zn}$ and $\mathrm{Mg}$ were determined by the enzyme-based immunoassay (EIA) system with the aid of an automated electrolyte analyzer, as described by Tietze (2012).

\section{Histological Study}

The tissues were dehydrated in ascending grades of ethanol, cleared in xylene and embedded in paraffin wax. Serial 7-micron thick sections were obtained using a rotary microtome. The de-paraffinized sections were stained routinely with hematoxylin and eosin. Photomicrographs of the desired results were obtained using an Olympus research photographic microscope according to the method described by Adjene et al. (2014).

\section{Statistical Analysis}

Data from this study were expressed as Mean \pm SEM and statistical significance of the treatment effect from this study was analyzed using one-way analysis of variance (ANOVA); inter group comparisons were performed with Tukey's post-hoc tests for randomized design using Graph Pad Prism, version $8 ; p<0.05$ was considered statistically significant.

\section{Statement on Ethical Clearance}

This study is part of a long-term study conducted under close supervision and as per the Delta State University standards with the written consent of the Research, Ethics and Grant committee of the Faculty of Basic Medical Sciences of the University (REC/FBMS/DELSU/18/05).

\section{Statement on Relevant Guidelines}

We also confirm that this study and the various experiments performed in it were carried out in accordance with the guidelines provided by the Research, Ethics and Grant committee of the Delta State University on the use of experimental animals and laboratory analysis.

\section{RESULTS}

The results are presented in Figures 1, 2, 3, 4, 5, 6 and 7; Tables 1 and 2; and Plate 1 . As presented in Figure 1, there was a statistically significant decrease in the testicular weight of the rats in the groups treated with $750 \mathrm{mg} /$ $\mathrm{kg}$ of phthalate for three $(0.67 \pm 0.07)$, five $(0.73 \pm 0.14)$, seven $(0.87 \pm 0.10)$, and nine weeks $(0.82 \pm 0.07)$ when compared with controls $(1.31 \pm 0.05)$ at a $p<0.05$. No significant differences were found between the experimental groups. Figure 2 shows that sperm count was significantly reduced in rats exposed to Phthalate for three $(38.83 \pm 12.01)$, five $(42.57 \pm 5.53)$, seven $(71.86 \pm 8.83)$, and nine weeks $(59.57 \pm 8.10)$ when compared with con-

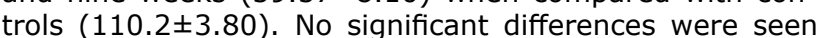
between the experimental groups. Figure 3 shows a statistically significant reduction in percent Sperm motility in the groups exposed to $750 \mathrm{mg} / \mathrm{kg}$ of phthalate for three

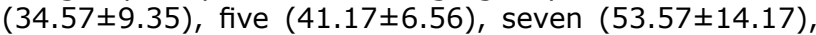
and nine weeks $(48.57 \pm 6.70)$ when compared with controls $(97.20 \pm 0.58)$. Figure 4 shows a statistically significant decrease in percent viable sperm cells in groups exposed to phthalate for three $(37.86 \pm 10.05)$, five $(51.67 \pm 16.77)$ and nine weeks $(44.29 \pm 6.40)$, respectively when com-

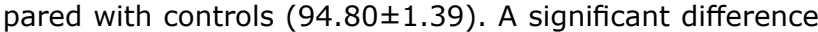
was observed between the groups treated for three weeks (37.86 \pm 10.05$)$ when compared with the group treated for one week $(77.14 \pm 6.16)$, although no significant differences were observed between the other experimental groups. Figure 5 shows a statistically significant increase in percent sperm cells with abnormal morphology in groups exposed to phthalate for three $(55.57 \pm 8.33)$, five $(50.86 \pm 5.69)$, seven $(46.86 \pm 11.43)$ and nine weeks $(57.57 \pm 6.32)$ when compared with controls $(10.14 \pm 1.68)$. No significant differences were seen between the groups treated for 3, 5, 7 , and 9 weeks.

Table 1 shows the effects of phthalate on gonadotropin and steroidal hormone levels of Male Wistar rats with different lengths of exposure. Accordingly, treatment with phthalate $(750 \mathrm{mg} / \mathrm{kg})$ led to a significant $(p<0.05)$ decrease in $\mathrm{LH}(1,3,5$ and 9 weeks), FSH $(1,3,5,7$ and 9 weeks), and testosterone (1, 3, 5, 7 and 9 weeks) levels when compared to controls. The results also showed a significant difference in LH in the rats treated for seven weeks when compared with rats treated for three and five weeks; the difference in testosterone levels in rats treated for three weeks was also significant when compared to the levels seen in rats treated for one week.

The effects of phthalate on serum electrolytes in Male Wistar rats following different lengths of exposure, as demonstrated in Figure 6 and 7, showed that chronic treatment with phthalate $(750 \mathrm{mg} / \mathrm{kg})$ produced a significant $(p<0.05)$ decrease in serum Zn levels (Figure 6) (rats treated for $1,3,5,7$ and 9 weeks) and a corresponding reduction $(p<0.05)$ in $\mathrm{Mg}$ levels (Figure 7$)$ when compared with controls.

Plates $1 \mathrm{~A}$ to $1 \mathrm{~F}$ show the histology of the testes of male Wistar rats following different lengths of exposure to phthalate. The slide for rats treated for one week displayed several atrophic seminiferous tubules and thickened 


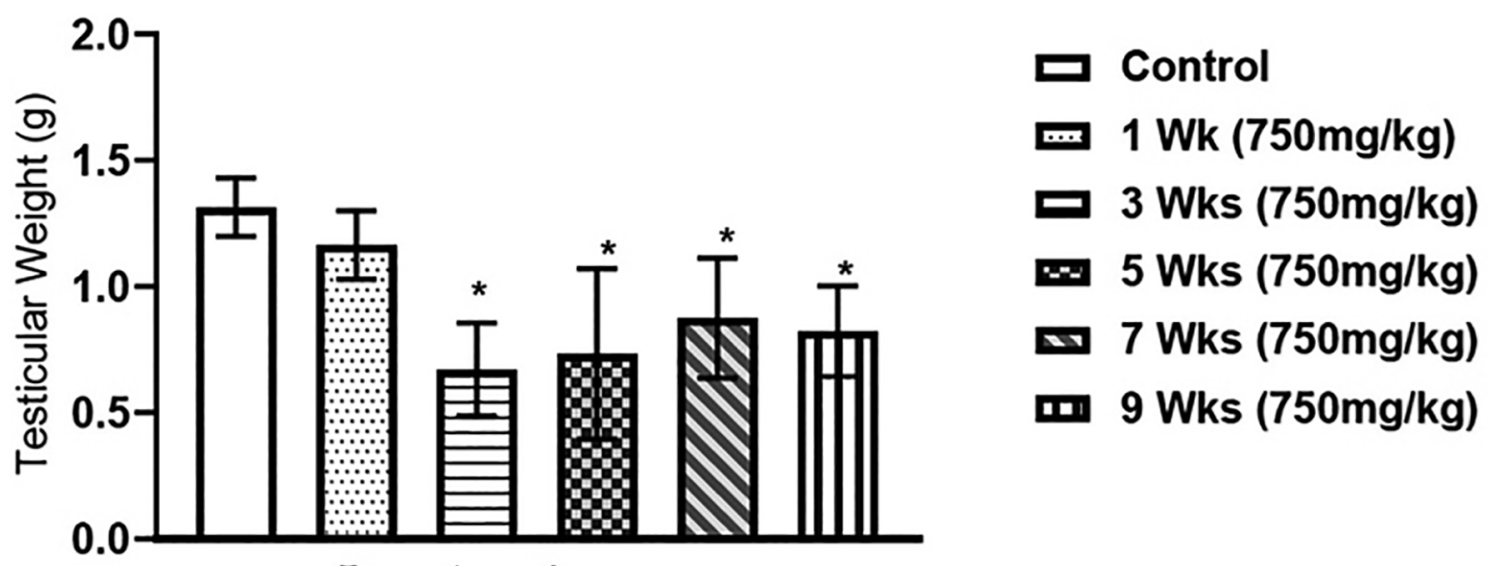

Duration of exposure

Figure 1. Effects of different lengths of exposure to phthalate on testicular weight in male Wistar rats Values are expressed as Mean \pm SEM $(n=7)$ (One-way ANOVA followed by Tukey's post hoc test).

$* p<0.05$ considered statistically significant when compared with controls.

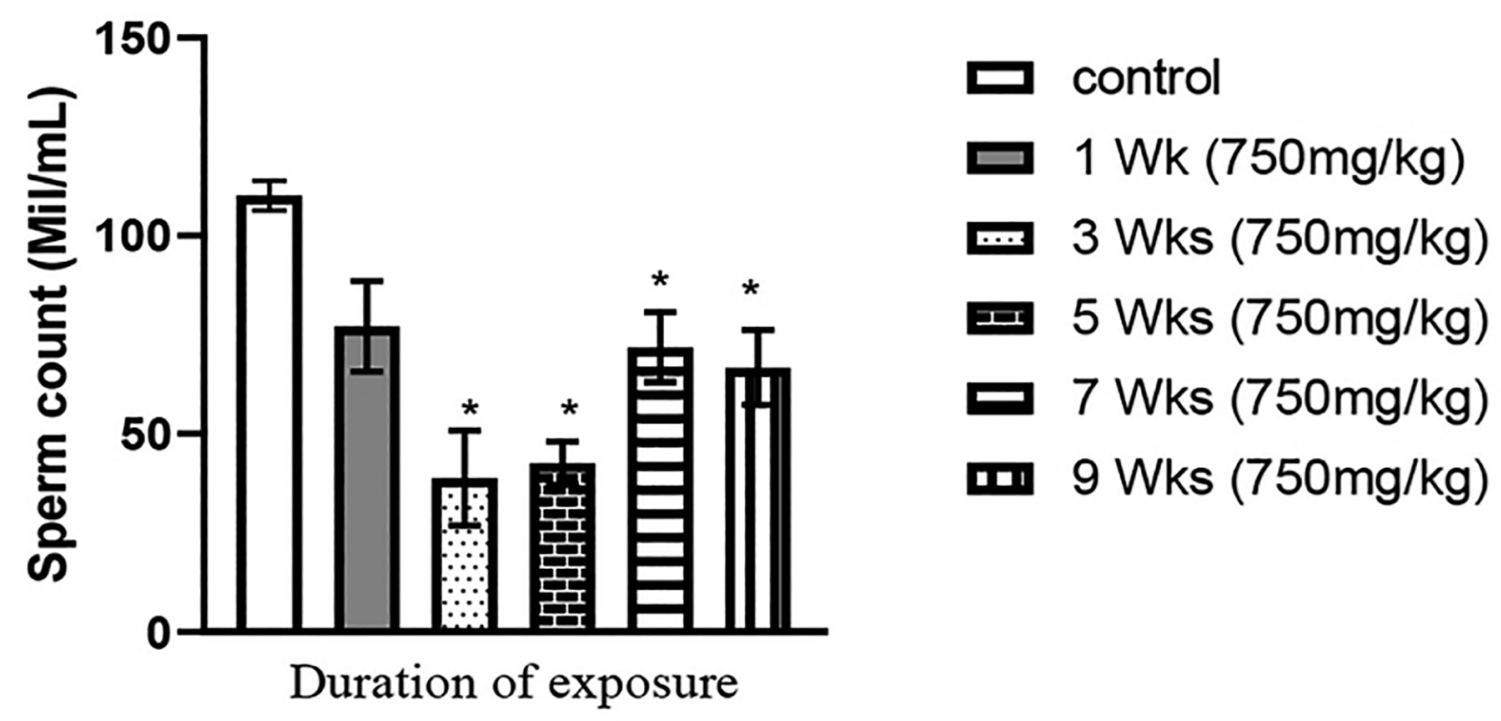

Figure 2. Effects of different lengths of exposure to phthalate on sperm count in male Wistar rats. Values are expressed as Mean \pm SEM $(n=7)$ (One-way ANOVA followed by Tukey's post hoc test). $* p<0.05$ considered statistically significant when compared with controls.

propria enveloping the tubules with degenerated germ cells and maturation arrest accompanied by mild congestion (Plate 1B). Rats treated for three weeks showed very poor testicular architecture with several bizzare shaped tubules, some atrophic seminiferous tubules and thickened propria enveloping the tubules with the presence of a pinkish homogenous mass and vascular congestion (Plate 1C). Rats treated for five weeks had very poor testicular architecture with several atrophic seminiferous tubules with thickened propria enveloping. This group also featured degenerated germ cells, maturation arrest and mild Leydig cells hyperplasia (Plate 1D). Rats treated for seven weeks showed moderately normal testicular architecture with normal seminiferous tubules and normal maturation stages with presence of spermatozoa within their lumen. However, few seminiferous tubules presented with maturation arrest and mild congestion when compared with normal controls (Plate $1 \mathrm{E}$ ). Rats treated for nine weeks had poor testicular architecture with some normal seminiferous tubules and normal maturation stages with spermatozoa within the lumen. However, congestion, some seminiferous tubules with fibrosis and degenerated epithelial germ cells and maturation arrest were also found. The interstitial spaces had normal Leydig cells (Plate $1 \mathrm{~F}$ ).

Table 2 shows the effects of the various lengths of exposure to phthalate on the seminiferous tubule count of the testes. The results showed a decline in the number of normal seminiferous tubules in groups treated with phthalate. Approximately $70 \%$ of the seminiferous tubules were normal in the group exposed for one week, $26.6 \%$ in the group exposed for three weeks, $21.4 \%$ in the group treated for five weeks, $60 \%$ in the group treated for seven weeks, and $55 \%$ in the group treated for nine weeks, against $100 \%$ in the control group. 


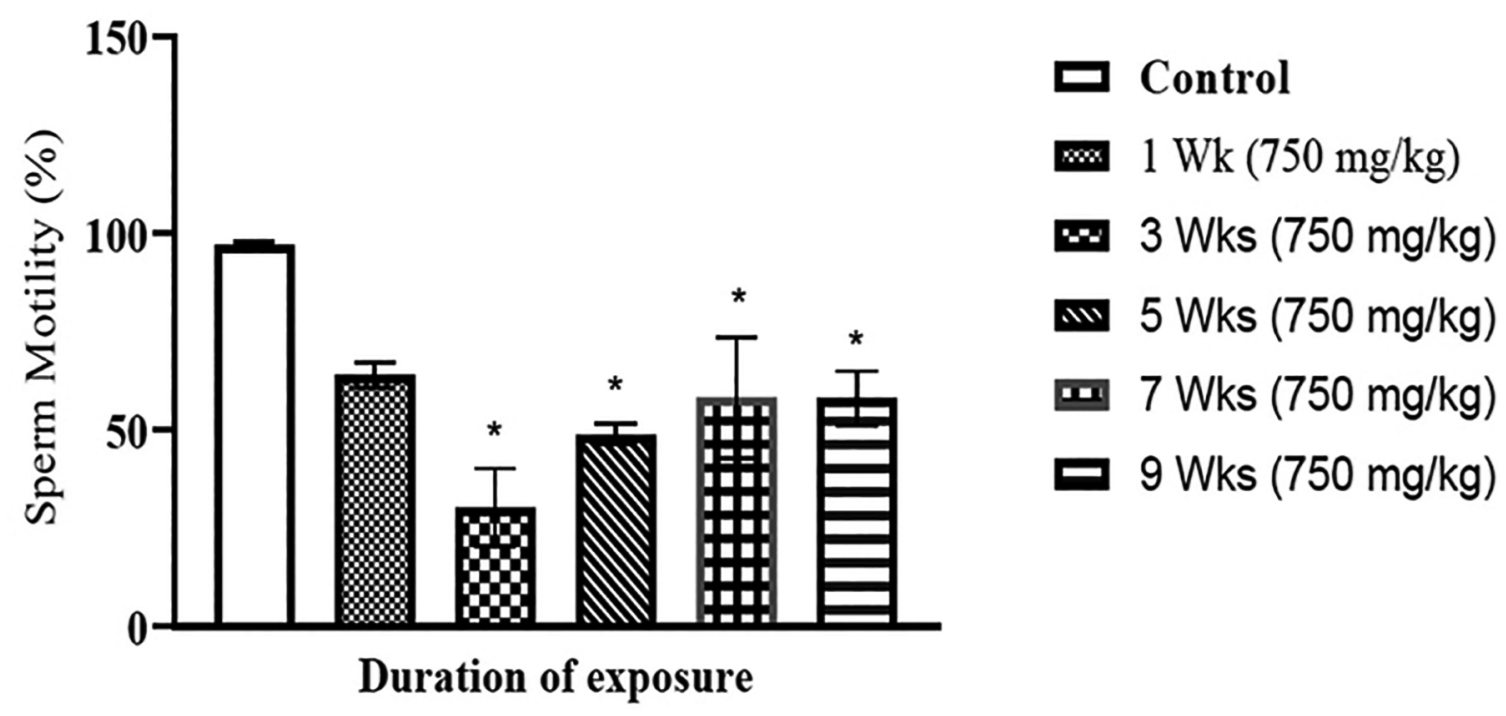

Figure 3. Effects of different lengths of exposure to phthalate on sperm motility in male Wistar rats Values are expressed as Mean \pm SEM $(n=7)$ (One-way ANOVA followed by Tukey's post hoc test). $* p<0.05$ considered statistically significant when compared with controls.

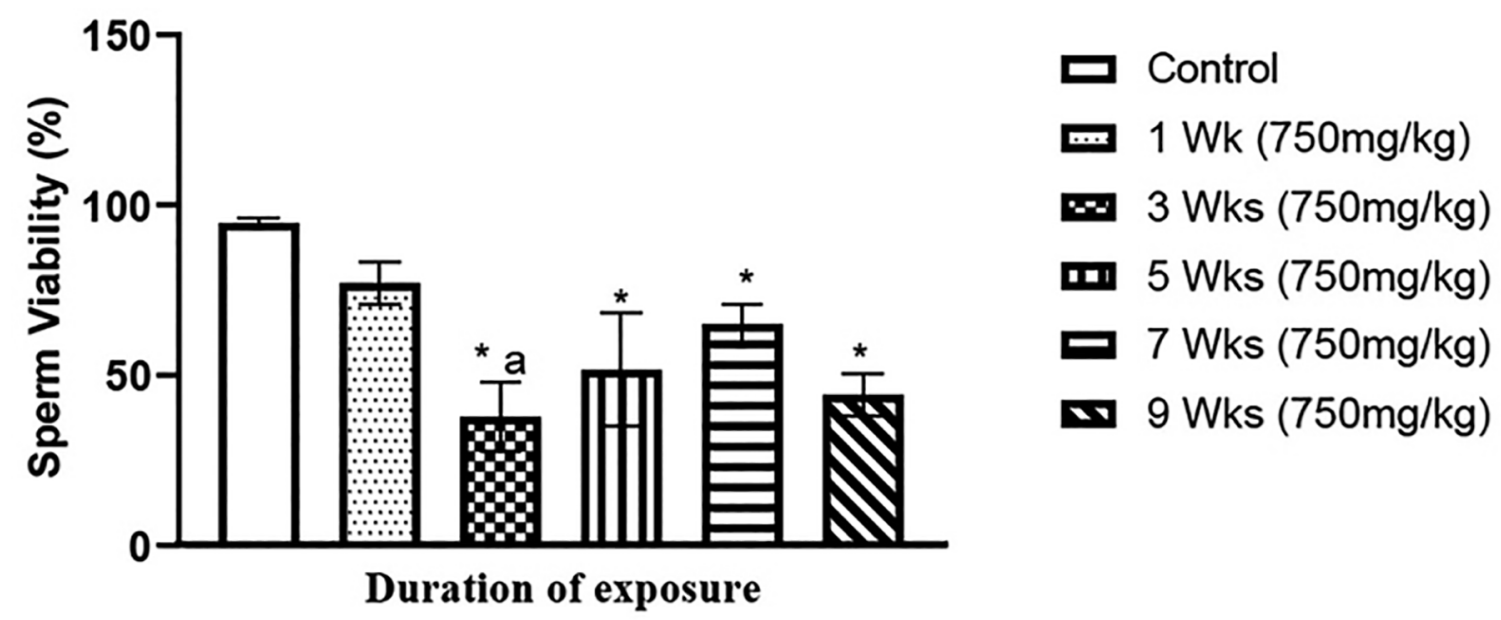

Figure 4. Effects of different lengths of exposure to phthalate on sperm viability in male Wistar rats Values are expressed as Mean \pm SEM $(n=7)$ (One-way ANOVA followed by Tukey's post hoc test). $*, a p 0.05$ were considered statistically significant when compared with controls and rats treated for one week, respectively.

\section{DISCUSSION}

The present study established the repro-toxic effects of different lengths of exposure to $750 \mathrm{mg} / \mathrm{kg}$ of phthalate on testicular weight and sperm characteristics such as sperm count, motility, viability and sperm morphology, in addition to the exact length of exposure that might cause such effects. In the study, testicular weight, testicular architecture, semen characteristics, serum zinc and magnesium levels were significantly affected by the administration of phthalate.

Organ weights are the fundamental benchmarks for toxicological studies (Crissman et al., 2004). Testicular weight was significantly decreased in groups exposed to phthalate for three, five, seven, and nine weeks relative to controls. This is an indication that phthalate may start affecting the weight of the testes significantly after three weeks of exposure. Studies on the consequences of toxic substances have demonstrated that the testes are more sensitive to endocrine disruptors than other important organs in the body (Schug et al., 2011). A recent study reported decreased testicular and epididymis weights and histopathology changes in testes of rat pups after perianal exposure to phthalate (Dobrzyńska, 2016). The reduction in weight observed in this study stands as a result of the degeneration of vital structures of the testes including the seminiferous tubules and Leydig cells, which account for more than $90 \%$ of the testicular mass. Degeneration of the seminiferous tubules signifies decreased numbers of Sertoli cells and germ cells. This degeneration may result from the release of excess reactive oxygen species (ROS) that lead to oxidative deterioration of proteins and lipids that eventually lead to atrophy (Akingbemi et al., 2004; Erkekoglu et al., 2014). This finding is consistent with a similar reduction in weight observed by Zhang et al. (2018) in pubertal rats following exposure to phthalate. 


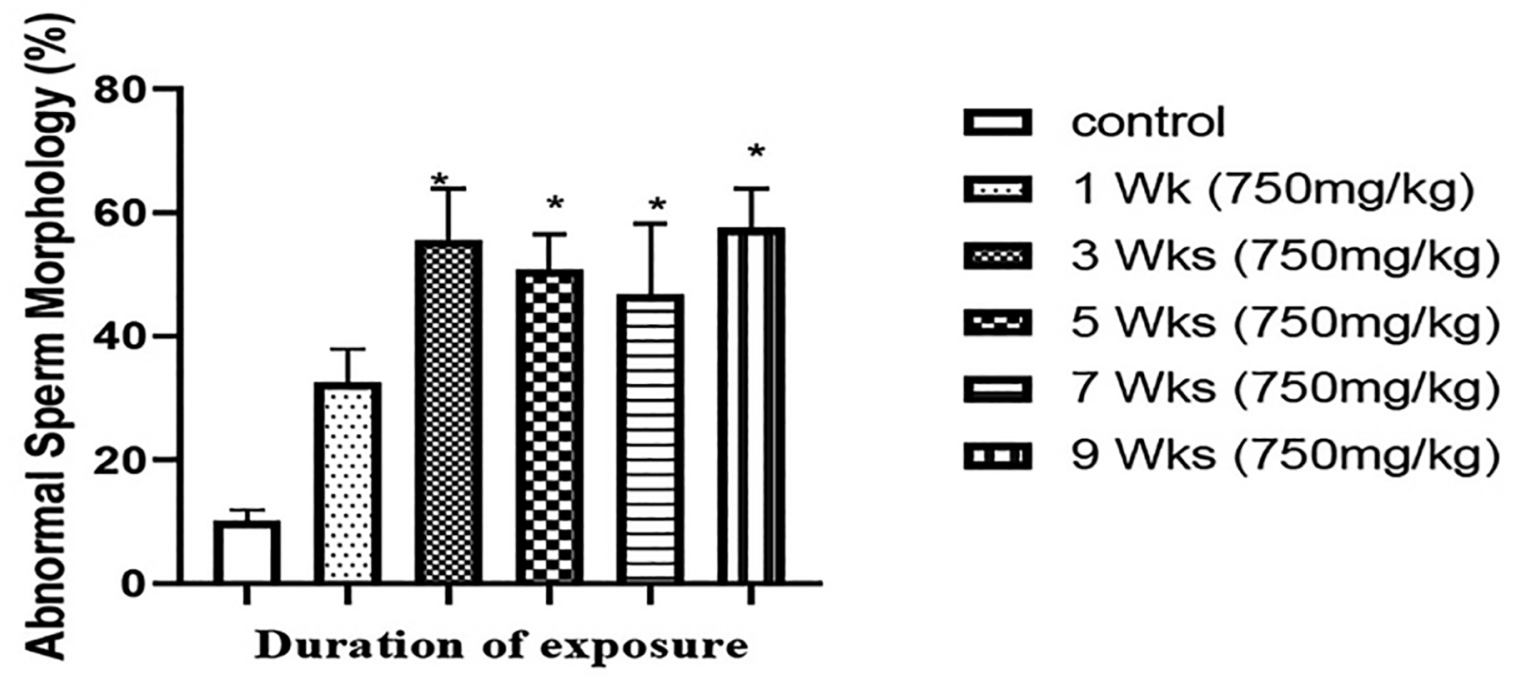

Figure 5. Effects of different lengths of exposure to phthalate on sperm morphology in male Wistar rats Values are expressed as Mean \pm SEM $(n=7)$ (One-way ANOVA followed by Tukey's post hoc test). $* p<0.05$ considered statistically significant when compared with controls.

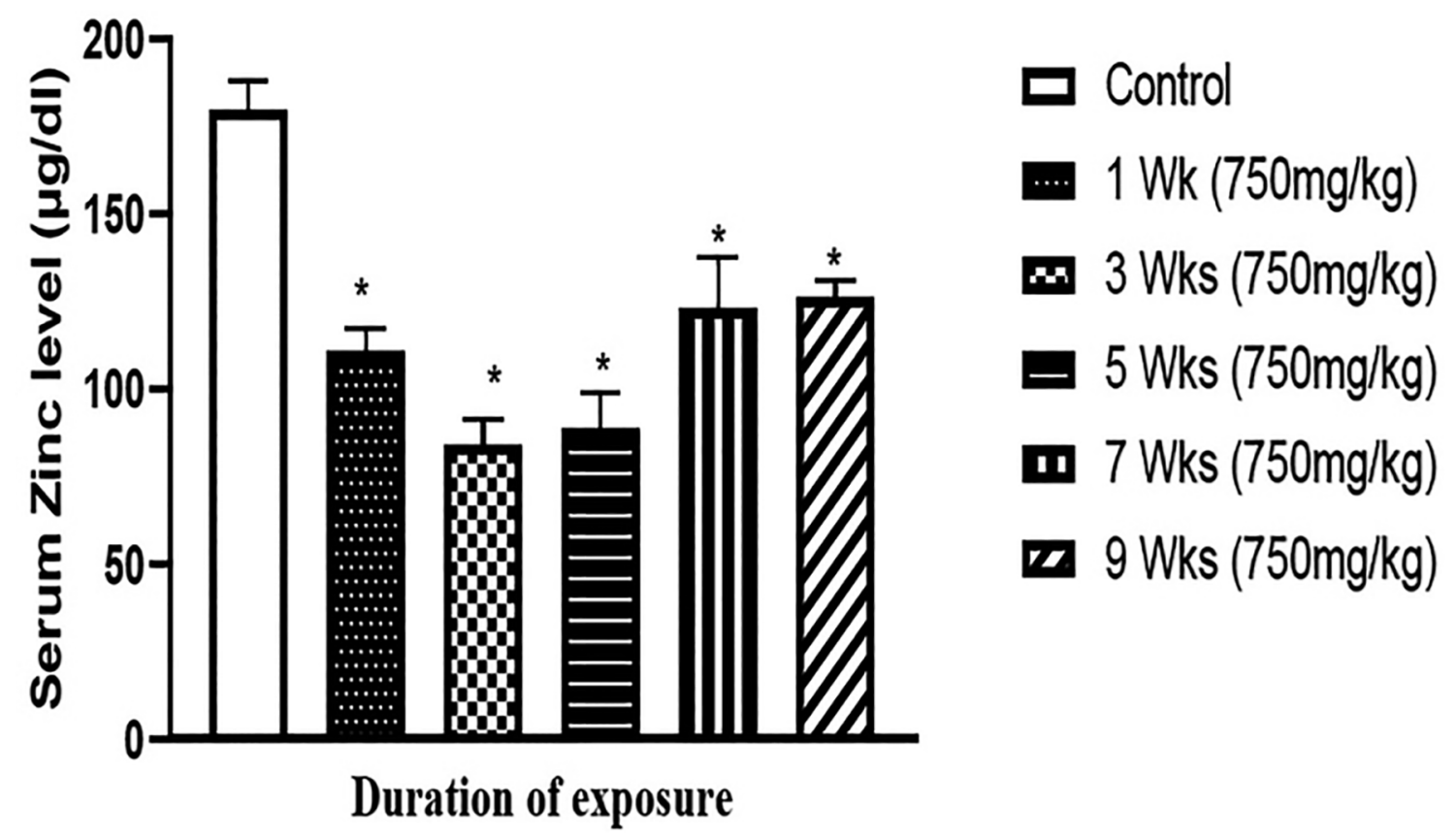

Figure 6. Effects of phthalate on serum Zn level in male Wistar rats following different lengths of exposure Values are expressed as Mean \pm SEM $(n=7)$ (One-way ANOVA followed by Tukey's post hoc test).

$* p<0.05$ when compared with controls.

Over the years, the quality and fertility potential of sperm has decreased dramatically as assessed by sperm count, sperm cell viability and motility, and sperm cell morphology (Darbre, 2015). Alterations in sperm parameters are indicative of poor testicular function (Durairajanayagam, 2018). The present study showed that phthalate significantly reduced sperm count (Figure 2 ), sperm motility (Figure 3 ) and viability (Figure 4) and increased abnormal sperm morphology (Figure 5) in the group exposed to 750 $\mathrm{mg} / \mathrm{kg}$ for three, five, seven, and nine weeks. This is due to the deleterious influence of phthalate on spermatogenesis. In the results there appears to be a slight improvement in the consistency of semen after the third week (although still significantly worse than controls). This suggests a certain degree of acclimatization, especially on week 7 of treatment, although the effects of phthalate were again pronounced at week 9 . This pattern further demonstrates the inability of the spermatogenic cells to completely acclimatize to phthalate-induced toxicity for a longer period. The present study agrees with the report of Subramanian et al. (2018), which reported a correlation between semen parameters and exposure to various toxic chemicals. Phthalate exerts this damaging effect on testicular function through decreases in serum testosterone and follicle stimulating hormone levels, degeneration of Leydig cells, or early detachment of germ cells from Sertoli cells due to the effects of phthalate in altering of zinc and magnesium homeostasis, as demonstrated in this study. When either of 


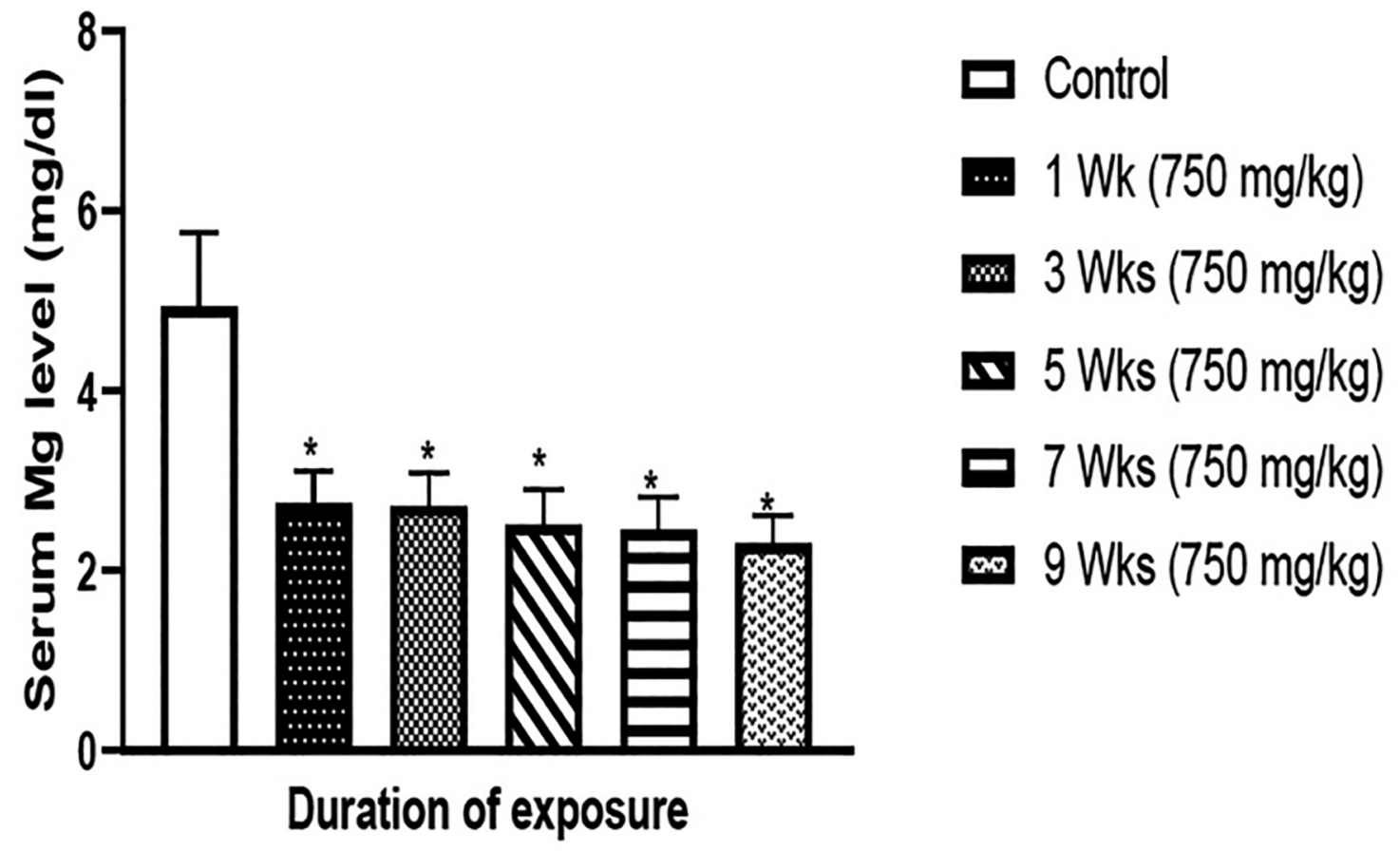

Figure 7. Effects of phthalate on serum Mg level in male Wistar rats following different lengths of exposure Values are expressed as Mean \pm SEM $(n=7)$ (One-way ANOVA followed by Tukey's post hoc test).

$* p<0.05$ considered statistically significant when compared with controls.

\begin{tabular}{|c|c|c|c|}
\hline GROUP & LH $(\mathrm{mUI} / \mathrm{ml})$ & FSH (mUI/mI) & Testosterone (ng/ml) \\
\hline A (Control) & $1.91 \pm 0.03$ & $3.05 \pm 0.15$ & $6.92 \pm 0.36$ \\
\hline B (1 Week) & $1.26 \pm 0.02 *$ & $2.55 \pm 0.11 *$ & $4.64 \pm 0.76 *$ \\
\hline C (3 Weeks) & $1.18 \pm 0.01 * d$ & $2.48 \pm 0.46 *$ & $2.22 \pm 0.25 * a$ \\
\hline D (5 Weeks) & $1.25 \pm 0.05 * d$ & $2.58 \pm 0.27 *$ & $2.86 \pm 0.18 *$ \\
\hline E (7 Weeks) & $1.68 \pm 0.16$ & $2.77 \pm 0.12 *$ & $3.90 \pm 0.60 *$ \\
\hline F (9 Weeks) & $1.28 \pm 0.06 *$ & $2.63 \pm 0.07 *$ & $3.47 \pm 0.03 *$ \\
\hline
\end{tabular}

Values are expressed as Mean \pm SEM $(n=7)$ (One-way ANOVA followed by Tukey's post hoc test).

$* a, d \quad p<0.05$ considered statistically significant when compared with controls and rats treated for one and seven weeks, respectively.

Table 2. Effects of different lengths of exposure to $750 \mathrm{mg} / \mathrm{kg}$ of phthalate on seminiferous Tubule Count of male Wistar rats.

\begin{tabular}{|l|c|c|c|c|c|}
\hline GROUP & nMA/field & nATR/field & nSL/field & nN/field & \% of Normal \\
\hline A (Control) & - & - & - & 38 & 100 \\
\hline B (1 Week) & 2 & 4 & 3 & 21 & 70 \\
\hline C (3 Weeks) & 2 & 29 & 2 & 3 & 26.6 \\
\hline D (5 Weeks) & 1 & 7 & - & 15 & 21.4 \\
\hline E (7 Weeks) & 2 & 7 & 8 & 18 & 60 \\
\hline F (9 Weeks) & 1 & 6 & 35 \\
\hline
\end{tabular}

MA: Maturation arrest, ATR: Atrophy, SL: Sloughed germ cells, N:Normal, n: Number 

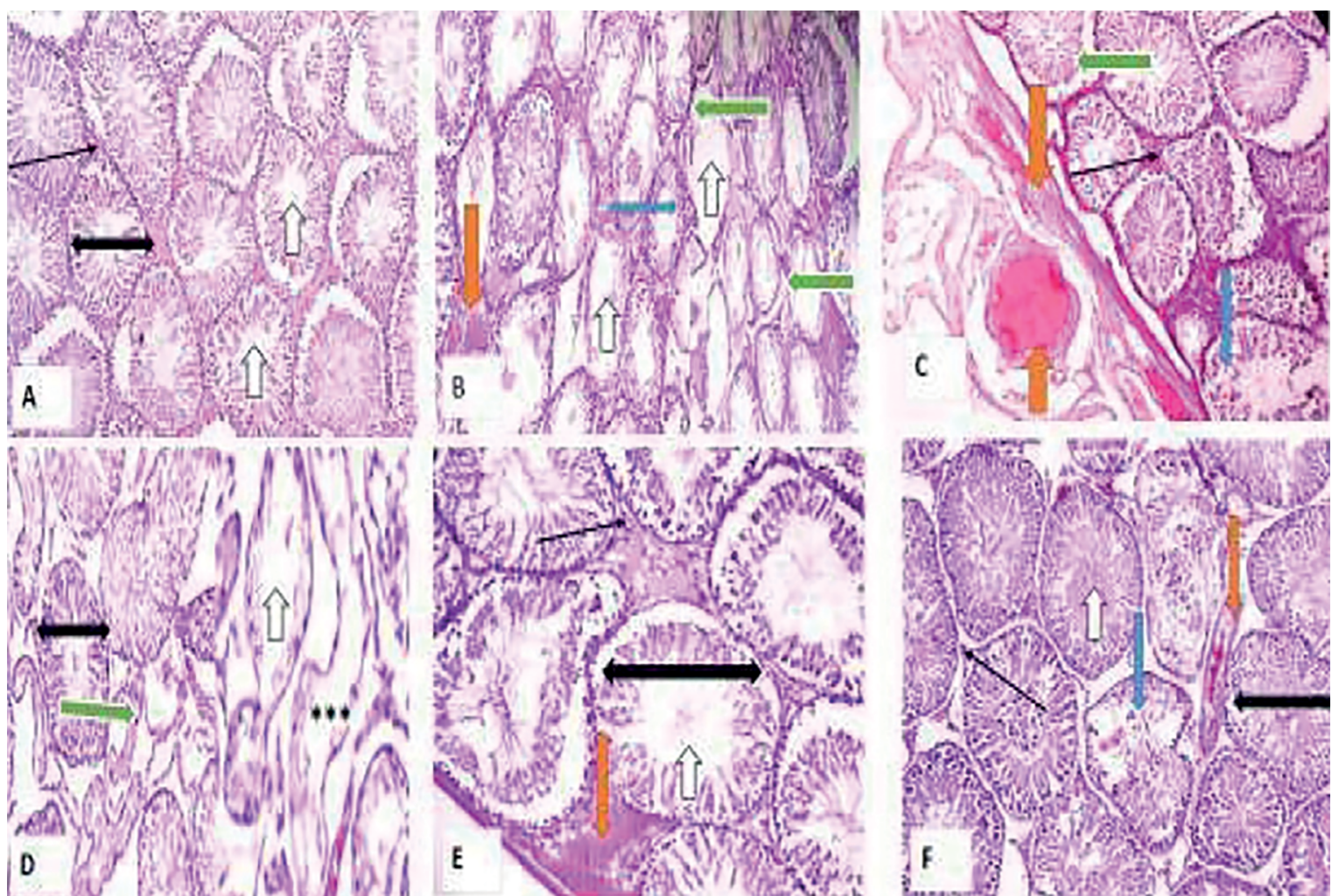

Plate 1. Effects of exposure of phthalate on histology of the testes of male Wistar rat following different lengths of exposure (H\&E stain $\times 100)$. A (control), B (1 week-PHT), C (3 weeks-PHT), D (5 weeks-PHT), $\mathrm{E}$ (7 weeks-PHT), F (9 weeks-PHT)

Normal Leydig cells (slender arrow); interstitial space with sperm cells (white arrow); seminiferous tubule (black span); vascular congestion (red arrow). Degenerated germ cells/Maturation Arrest (blue arrow). Thickened propria enveloping the tubules (green arrow), poor architecture (***).

these happens, the development of secondary spermatocytes to spermatids may be hampered due to lack of nourishment of the germ cells (Murphy \& Richburg, 2015) due to their interdependent nature (Saradha et al., 2009; Murphy \& Richburg, 2015). Several studies have linked the effects of phthalate on semen parameters to the generation of reactive oxygen species (ROS) at a cellular level (Song et al., 2019). Effects include increased lipid peroxidation (da Silva et al., 2016), disrupted cell function, and altered expression and activity of the most important antioxidant enzymes, thus leading to testicular tissue damage, germ cell apoptosis, and reduced spermatogenesis (Wagner et al., 2017; Wójtowicz et al., 2019).

During spermatogenesis, although germ cell apoptosis is said to be a normal occurrence that increases when Sertoli cells are injured and can no longer support their normal complement of germ cells, germ cell apoptosis might also be induced through direct injury by a toxicant (Murphy \& Richburg, 2015), as demonstrated in this study. Reduction in follicle stimulating hormone alongside germ cell apoptosis as a result of increased activity of reactive species have also accounted for the poor semen parameters observed in this study.

\section{CONCLUSION}

Our study showed that phthalate decreased the weight of the testes and sperm quality. These deleterious effects of phthalate were observed as early as after one week of exposure and became very prominent as of three weeks of exposure. Failed cell acclimatization seems to have occurred after seven weeks of exposure. This deleterious effect of Phthalate was attributed to electrolyte (zinc and magnesium) derangement, endocrine disruption and alteration of testicular architecture.

\section{ACKNOWLEDGEMENT}

The authors wish to acknowledge Mrs. Eloho Cynthia Emojevwe for financial and moral support during the research.

\section{Authors' contribution}

EV wrote the manuscript; NAO and NEK conceived and designed the study and contributed with reagents and analytical tools; AKM \& EV conducted experiments; OMO collected samples and analyzed the data; AE edited the manuscript, supplied laboratory resources and analyzed the samples with AKM; TME also contributed with reagents and analyzed samples with AKM. All authors read and approved the manuscript.

\section{CONFLICT OF INTEREST}

The authors have no conflicts of interest to declare.

\section{Corresponding author:}

Victor Emojevwe

Department of Physiology,

University of Medical Sciences,

Ondo, Ondo State, Nigeria

E-mail: vemojevwe@unimed.edu.ng 


\section{REFERENCES}

Adjene JO, Emojevwe V, Igbigbi PS. Morphological effects of long-term consumption of energy drinks on the intracranial visual relay centres of adult wistar rats. Anat J Afr. $2014 ; 3: 275-85$.

Akingbemi BT, Ge R, Klinefelter GR, Zirkin BR, Hardy MP. Phthalate-induced Leydig cell hyperplasia is associated with multiple endocrine disturbances. Proc Natl Acad Sci U S A. 2004;101:775-80. PMID: 14715905 DOI: 10.1073/ pnas.0305977101

Benjamin S, Masai E, Kamimura N, Takahashi K, Anderson RC, Faisal PA. Phthalates impact human health: Epidemiological evidences and plausible mechanism of action. J Hazard Mater. 2017;340:360-83. PMID: 28800814 DOI: 10.1016/j.jhazmat.2017.06.036

Chang $\mathrm{WH}$, Li SS, Wu MH, Pan HA, Lee CC. Phthalates might interfere with testicular function by reducing testosterone and insulin-like factor 3 levels. Hum Reprod. 2015;30:2658-70. PMID: 26385792 DOI: 10.1093/humrep/dev225

Crissman JW, Goodman DG, Hildebrandt PK, Maronpot RR, Prater DA, Riley JH, Seaman WJ, Thake DC. Best practices guideline: toxicologic histopathology. Toxicol Pathol. 2004;32:126-31. PMID: 14713558 DOI: $10.1080 / 01926230490268756$

da Silva RF, Borges Cdos S, Villela E Silva P, Missassi G, Kiguti LR, Pupo AS, Barbosa Junior F, Anselmo-Franci JA, Kempinas Wde G. The Coadministration of N-Acetylcysteine Ameliorates the Effects of Arsenic Trioxide on the Male Mouse Genital System. Oxid Med Cell Longev. 2016;2016:4257498. PMID: 26839632 DOI: $10.1155 / 2016 / 4257498$

Darbre PD. Endocrine Disruption and Male Reproductive Health. In: Darbre PD, ed. Endocrine Disruption and Male Reproductive Health. London: Academic Press, Elsevier; 2015. p. 159-75.

Dobrzyńska MM. Phthalates - widespread occurrence and the effect on male gametes. Part 2. The effects of phthalates on male gametes and on the offspring. Rocz Panstw Zakl Hig. 2016;67:209-21. PMID: 27546318

Durairajanayagam D. Lifestyle causes of male infertility. Arab J Urol. 2018;16:10-20. PMID: 29713532 DOI: 10.1016/j.aju.2017.12.004

Erkekoglu P, Zeybek ND, Giray BK, Rachidi W, Kızılgün M, Hininger-Favier I, Favier A, Asan E, Hincal F. The effects of di(2-ethylhexyl)phthalate on rat liver in relation to selenium status. Int J Exp Pathol. 2014;95:64-77. PMID: 24180374 DOI: 10.1111/iep.12059

Esteves SC. Clinical relevance of routine semen analysis and controversies surrounding the 2010 World Health Organization criteria for semen examination. Int Braz J Urol. 2014;40:443-53. PMID: 25254609 DOI: 10.1590/S16775538.IB]U.2014.04.02

Kamrin MA. Phthalate risks, phthalate regulation, and public health: a review. J Toxicol Environ Health B Crit Rev. 2009;12:157-74. PMID: 19235623 DOI: $10.1080 / 10937400902729226$
Khatun A, Rahman MS, Pang MG. Clinical assessment of the male fertility. Obstet Gynecol Sci. 2018;61:179-91. PMID: 29564308 DOI: 10.5468/ogs.2018.61.2.179

Lee E, Ahn MY, Kim HJ, Kim IY, Han SY, Kang TS, Hong JH, Park KL, Lee BM, Kim HS. Effect of di(n-butyl) phthalate on testicular oxidative damage and antioxidant enzymes in hyperthyroid rats. Environ Toxicol. 2007;22:245-55. PMID: 17497641 DOI: $10.1002 /$ tox.20259

Murphy $\mathrm{CJ}$, Richburg $\mathrm{JH}$. Implications of Sertoli cell induced germ cell apoptosis to testicular pathology. Spermatogenesis. 2015;4:e979110. PMID: 26413394 DOI: $10.4161 / 21565562.2014 .979110$

Nassouri AS, Archambeaud F, Desailloud R. [Endocrine disruptors: echoes of congress of Endocrinology in 2012]. Ann Endocrinol (Paris). 2012;73:S36-44. French. PMID: 23089380 DOI: 10.1016/S0003-4266(12)70013-6

Omirinde JO, Olukole SG, Oke BO. Age-related changes in the testicular and epididymal sperm parameters in the African greater cane rat (Thryonomys Swinderianus, Temminck, 1827). Anim Res Int. 2019;16:3255-64.

Saradha B, Vaithinathan S, Mathur PP. Lindane induces testicular apoptosis in adult Wistar rats through the involvement of Fas-FasL and mitochondria-dependent pathways. Toxicology. 2009;255:131-9. PMID: 19038305 DOI: $10.1016 /$ j.tox.2008.10.016

Schug TT, Janesick A, Blumberg B, Heindel JJ. Endocrine disrupting chemicals and disease susceptibility. J Steroid Biochem Mol Biol. 2011;127:204-15. PMID: 21899826 DOI: $10.1016 /$ j.jsbmb.2011.08.007

Silins I, Högberg J. Combined toxic exposures and human health: biomarkers of exposure and effect. Int J Environ Res Public Health. 2011;8:629-47. PMID: 21556171 DOI: 10.3390/ijerph8030629

Song P, Gao J, Li X, Zhang C, Zhu L, Wang J, Wang J. Phthalate induced oxidative stress and DNA damage in earthworms (Eisenia fetida). Environ Int. 2019;129:10-7. PMID: 31102950 DOI: 10.1016/j.envint.2019.04.074

Subramanian V, Ravichandran A, Thiagarajan N, Govindarajan $M$, Dhandayuthapani $S$, Suresh $S$. Seminal reactive oxygen species and total antioxidant capacity: Correlations with sperm parameters and impact on male infertility. Clin Exp Reprod Med. 2018;45:88-93. PMID: 29984209 DOI: 10.5653/cerm.2018.45.2.88

Tietze KJ. Review of Laboratory and Diagnostic Tests. In: Tietze KJ. Clinical Skills for Pharmacists. 3rd ed. Saint Louis: Mosby; 2012; p. 86-122.

Wagner $\mathrm{H}$, Cheng JW, Ko EY. Role of reactive oxygen species in male infertility: An updated review of literature. Arab J Urol. 2017;16:35-43. PMID: 29713534 DOI: 10.1016/j. aju.2017.11.001

Wójtowicz AK, Sitarz-Głownia AM, Szczęsna M, Szychowski KA. The Action of Di-(2-Ethylhexyl) Phthalate (DEHP) in Mouse Cerebral Cells Involves an Impairment in Aryl Hydrocarbon Receptor (AhR) Signaling. Neurotox Res. 2019;35:183-95. PMID: 30120713 DOI: $10.1007 /$ s12640018-9946-7 
Wu CT, Wang CC, Huang LC, Liu SH, Chiang CK. Plasticizer Di-(2-Ethylhexyl)Phthalate Induces Epithelial-to-Mesenchymal Transition and Renal Fibrosis In Vitro and In Vivo. Toxicol Sci. 2018;164:363-74. PMID: 29669060 DOI: $10.1093 /$ toxsci/kfy094

Yavaşoğlu NÜ, Köksal C, Dağdeviren M, Aktuğ H, Yavaşoğlu A. Induction of oxidative stress and histological changes in liver by subacute doses of butyl cyclohexyl phthalate. Environ Toxicol. 2014;29:345-53. PMID: 22936646 DOI: 10.1002/tox.21813
Yu S, Rubin M, Geevarughese S, Pino JS, Rodriguez HF, Asghar W. Emerging technologies for home-based semen analysis. Andrology. 2018;6:10-9. PMID: 29194998 DOI: 10.1111/andr. 12441

Zhang L, Li H, Gao M, Zhang T, Wu Z, Wang Z, Chong T. Genistein attenuates di ( 2 ethylhexyl) phthalate-induced testicular injuries via activation of $\mathrm{Nrf2/HO} 1$ following prepubertal exposure. Int J Mol Med. 2018;41:1437-46. PMID: 29328408 DOI: 10.3892/ijmm.2018.3371 